\title{
Optical Channel Capacity Upgrade Based on Multiwavelength Conversion XGM Using Semiconductor Optical Amplifier for Access Networks
}

\author{
Mohammad Syuhaimi Ab-rahman and Abdul Hameed Almabrok Swedan \\ Department of Electrical, Electronic \& System Engineering, Faculty of Engineering and Built Environment, \\ Universiti Kebangsaan Malaysia (UKM), Bangi, Selangor, Malaysia \\ Correspondence should be addressed to Abdul Hameed Almabrok Swedan; aswsw2002@yahoo.com
}

Received 2 November 2016; Accepted 21 February 2017; Published 4 April 2017

Academic Editor: Sulaiman Wadi Harun

Copyright (C) 2017 Mohammad Syuhaimi Ab-rahman and Abdul Hameed Almabrok Swedan. This is an open access article distributed under the Creative Commons Attribution License, which permits unrestricted use, distribution, and reproduction in any medium, provided the original work is properly cited.

\begin{abstract}
This paper demonstrates a $10 \mathrm{~Gb} / \mathrm{s}$ one-to-two-wavelength conversion configuration based on cross-gain modulation for optical access networks using a single TW-SOA. The method is capable of converting a signal data of specific wavelength $1541 \mathrm{~nm}$ to certain wavelengths of CW's laser $1554 \mathrm{~nm}$ and $1558 \mathrm{~nm}$ with $4 \mathrm{~nm}$ spacing. The pump power level was classified due to channel response. A result obtained was the best power level offering wavelength converter between -6 and $3 \mathrm{dBm}$. The conversion efficiency achievement provided an acceptable result for probe signals. The findings of $Q$-factor performance were investigated. The $Q$ values were found to be more than 9 for point to point transmission and $20 \mathrm{~km}$ fiber configurations for the original and converted signal. The technique implemented at $20 \mathrm{~km}$ and the power of all channels were adequate to provide a splitting ratio of 1/64 for the launched pump power $3 \mathrm{dBm}$.
\end{abstract}

\section{Introduction}

New services and applications for data exchange over wireless and mobile network access points (AP) in telecommunication networks have recorded numerous increase of average bandwidth downloaded by each customer for different requirements, which led to high demands for big capacity data exchange system. They grew rapidly very close together pushing current systems to upgrade their configurations and standards to cope with these requirements [1-5]. Semiconductor marital has advanced regarding its fabrication process, device design, and applications. The semiconductor optical amplifier (SOA) has indicated a substantial potential for alloptical data processing applications and is distinguished as a multifunction device [6-12]. Moreover, multiwavelength converter (MWC) based on SOA has gained the attention of researchers due to its relatively small size, easy integration, and low power consumption [13-15].

There are two operating regions of SOA, amplification region and a saturation region. SOA that works in the saturation region increases the effect of nonlinear behaviors such as cross-gain modulation (XGM), cross-phase modulation (XPM), and four-wave mixing (FWM) [16-20]. There are many parameters which guided the output characteristics of SOA under this situation; the pump power played as the key factor that controlled the behavior of SOA outputs responses. Many articles have examined wavelength conversion for wavelength division multiplexing (WDM) in the past. Some of these researchers have studied the wavelength converter (WC) at optical line terminal (OLT) increasing the number of wavelengths. Others run the WC at optical network unit (ONU) using a reflective semiconductor optical amplifier (RSOA) for upstream transmission. Nevertheless, these architectures need to install erbium-doped fiber amplifier (EDFA) [21-24]. The literature does not clarify the importance of the SOA position. Recently, the capacity requirement has figured out the bottleneck in ONU regarding the number of users and download speed demands. For this purpose, the performance of MWC based on XGM for two channels at ONU was presented and investigated. Besides, the pump 
TABLE 1: Pump power classification for proposed system.

\begin{tabular}{lcccc}
\hline Case & Pump power $(\mathrm{dBm})$ & Pump $1541 \mathrm{~nm}$ & CW1554 $\mathrm{nm}$ & \\
\hline $\mathrm{a}$ & $-36,-33$ & $X$ & $X$ & CW1558 $\mathrm{nm}$ \\
$\mathrm{b}$ & -30 to -9 & $\sqrt{ }$ & $X$ & $X$ \\
$\mathrm{c}$ & -6 to 3 & $\sqrt{ }$ & $\sqrt{ }$ & $X$ \\
\hline
\end{tabular}

power level was demonstrated to find out the suitable position of MWC. For the system implementation, the investigation and analyzing of MWC are required. There are several features of installing the MWC at (ONU) distribution access area: firstly, brown and cost-effective solution using old OLT and the old fiber link and also the proposed model avoiding WDM issues once wavelengths at OLT increase; additionally the architecture enabled the service provider to offer more bandwidth to the clients as the new services grow. Moreover, the scheme can be arranged for coexistence with the standard systems.

The aim of this article is to evaluate the impact of pump power on the performance of 1-to-2-XGM wavelength converters at different positions of SOA along an optical link. In addition, the effect of optical power splitter regarding splitting ratio was demonstrated for three values. The wideband steady-state numerical model presented in [25] was adopted by Opti.System ${ }^{\odot}$ software which was used in this work to verify the configuration results. The model was used to analyze the carrier density rate equation and the output power, which was presented in $[26,27]$. Furthermore, the conversion efficiency (CE) was calculated to identify the wavelength converter. The impact of splitting ratio on the pump performance and probes channels at ONU was investigated in this paper.

This article is organized as follows: the system configuration and operational principle are described in the next section. For Section 3, the theory of the TW-SOA model is explained. In Section 4, the results of proposed scheme for three parameters are presented and later the conversion efficiency of the converted signals and its dependence on the pump power and output power of converted channels are measured. Additionally, this paper gives special attention to study the impact of pump power relative to the position of SOA. Thus, the splitting ratio impact on performance was investigated. Lastly, in Section 5 the result of this research is concluded.

\section{System Configuration and Operational Principle}

One advantage of SOA is that it can work in the saturation region, where the gain of probe signal can be modulated according to modulated pump signal data. The cross-gain modulation (XGM) stage consists of optical coupler or multiplexer (MUX) to combine pump signal and probe signals are followed by semiconductor optical amplifier as nonlinear element; in this work the structure utilizes travelling-wave SOA; XGM idea is that if one or more continuous wave (CW) probe wavelengths combine with the pump and pass through the SOA, the probes will be subjected to gain modulation and be optically modulated to carry the inverted bit sequence of pump signal. The $1541 \mathrm{~nm}$ pump wavelength modulated the two CWs lasers $1554 \mathrm{~nm}$ and $1558 \mathrm{~nm}$ with $0 \mathrm{dBm}$ powers. Then, the output of SOA is filtered to separate the original and converted channels, and polarization control (PC) was used to adjust each laser. After that, different wavelengths were received, and the system performance was demonstrated. To verify XGM process the CE was measured. The configuration used to investigate the wavelength converter was displayed in Figure 1. Finally, this paper focuses on the signal quality of original and converted wavelengths after the optical splitter.

Table 1 shows that the SOA output responses of the pump and probes with $200 \mathrm{~mA}$ injected electric current when the pump power is varied from -36 to $3 \mathrm{dBm}$. Once the pump power is high enough it can categorize which WC takes place in the power range from -6 to $3 \mathrm{dBm}$ associated with SOA saturation region. It can be seen that, for low values of input power, the SOA cannot respond to the pump input change. However, when pump power was increased the pump signal responded to the power change, and the SOA linear region was -30 to $-9 \mathrm{dBm}$. Therefore, the XGM was implemented on the power range of -6 to $3 \mathrm{dBm}$ for two wavelengths with $4 \mathrm{~nm}$ spacing.

The SOA position is very important. The WC was tested at three positions as described in Figure 1. First, the WC was applied at central office point to point no fiber link. Then, the SOA-WC device was installed at $20 \mathrm{~km}$ fiber, which is the regular distance of passive optical networks, and finally the third architecture was elaborated for $20 \mathrm{~km}$ with a splitting ratio of $1 / 64$. In addition, the effect of the splitting ratio was validated at three splitting ratios: $1 / 16,1 / 32$, and $1 / 64$. We examined the pump power functionality closely at every point, which will influence the response of the pump and probe signals after demultiplexing (DMUX). After some iterative tests, we established optimal conditions to classify the pump power operation that can be an adequate level to implement the wavelength conversion as shown in Table 1.

The pump signal data can convert into each probe depending on the pump power and wavelength. The system showed good performance, for both probes at $3 \mathrm{dBm}$ pump power with $20 \mathrm{Km}$ and splitting ratio $1 / 64$, while using the splitting ratio of $1 / 32$ the system can present at $0 \mathrm{dBm}$. Tunable WC can be made available in access networks by filtering out multiple wavelengths of CW's probes using DMUX and then transmits them to different users.

\section{Mathematical Background}

When the power passed through SOA, the output power $\left(P_{\text {out }}\right.$ at the length $L$ described in [28]) can be calculated from

$$
P_{\text {out }}=\frac{1}{L} \int_{0}^{L} P_{\text {in }} \times g d z,
$$




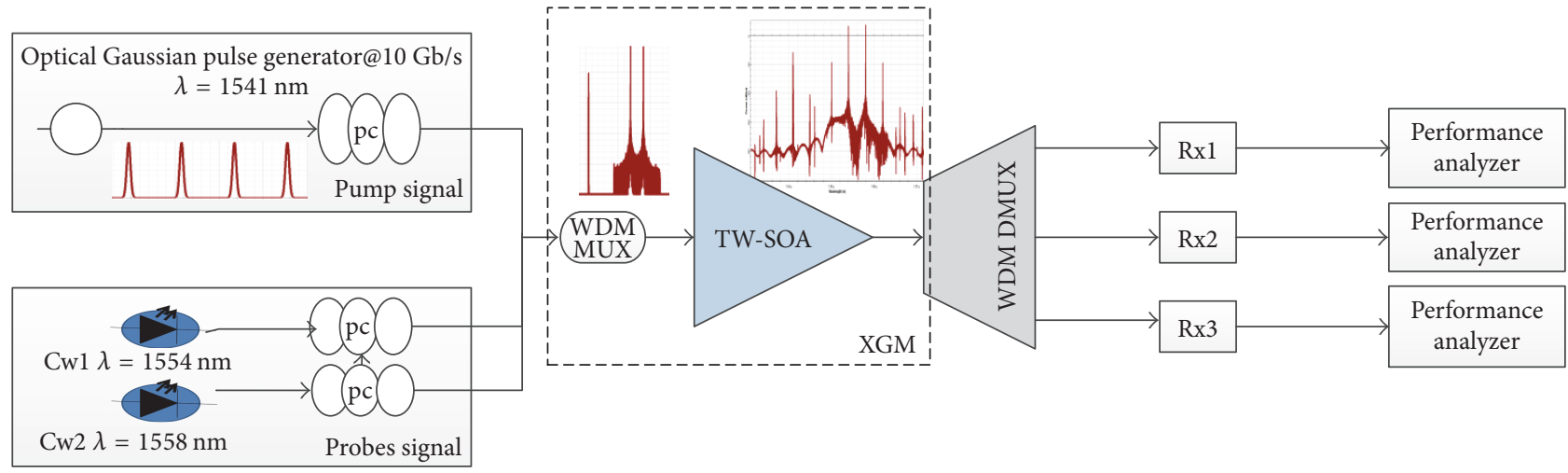

(a)

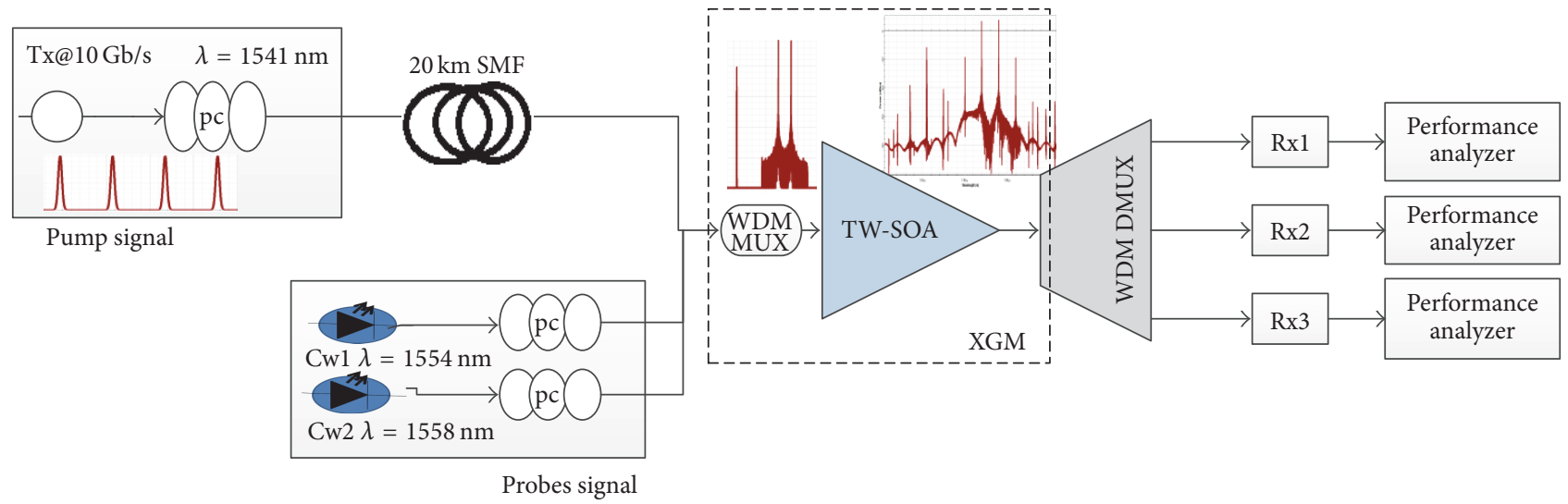

(b)

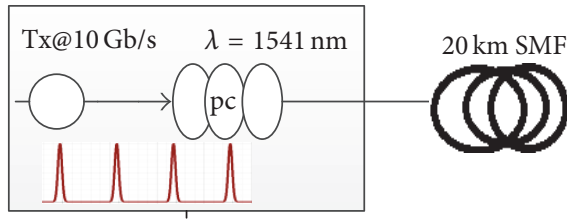

Pump signal

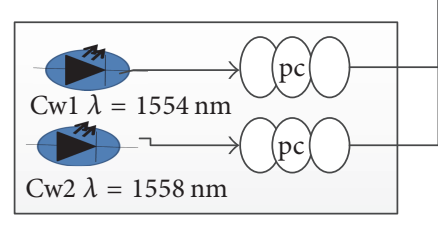

Probes signal

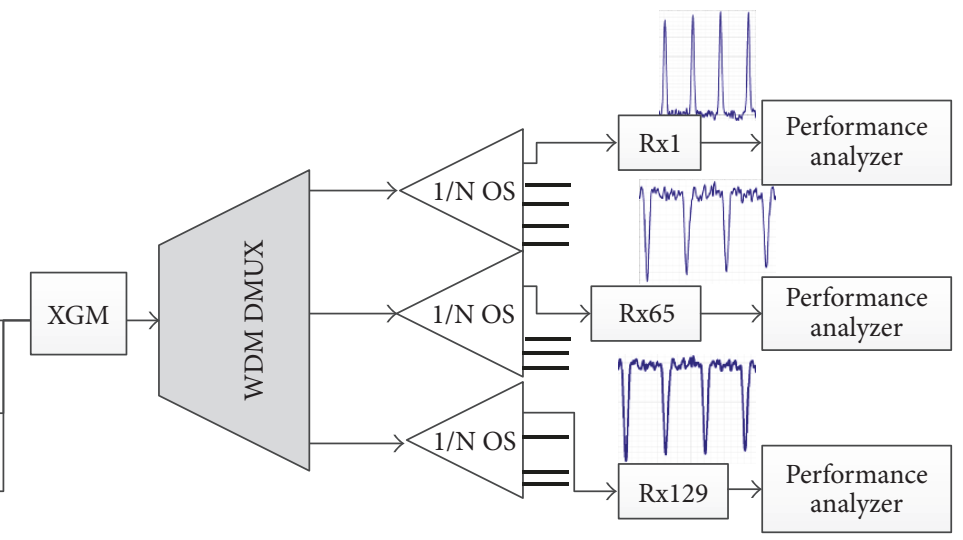

(c)

FIgURE 1: System configuration: (a) point to point no fiber at (b) $20 \mathrm{~km} \mathrm{SMF}$ and (c) $20 \mathrm{Km}$ SMF + optical splitter.

where $P_{\text {in }}$ is the input signal power, $L$ is the active region length, and $g$ is the total gain at location $z$ of SOA. Next, the active volume of the amplifier was determined by $V=L \times W \times$ $d$, where $W$ is the width and $d$ is the thickness of the active region. With the power changed along the device the carrier and photon density had fluctuations over the active region which can be explained using the rate equations. Steady-state numerical model clarified in $[25,26]$ was considered to verify the wavelength converter and optimize the SOA for a given application. In the mathematical model, the SOA was divided into some sections. The carrier density rate of change, $N$ inside the active region of the amplifier (in section $i$ ) at time $(t)$, is given by

$$
\begin{aligned}
& \frac{d N_{i}(z)}{d t}=\frac{I}{e d L W}-R\left(N_{i}(z)\right)-\frac{\Gamma}{h d W} \\
& \quad \times\left\{\sum_{k=1}^{N s} \frac{g\left[N_{i}(z), v_{k}\right]}{v_{k}} p_{k}(z, t)\right\}
\end{aligned}
$$


TABle 2: Parameters utilized in the scheme.

\begin{tabular}{lccr}
\hline Parameter & Symbol & Connelly [25] & Our configuration \\
\hline Input signal wavelength & $\lambda_{\text {Pump }}$ & $1537.7 \mathrm{~nm}$ & $1541 \mathrm{~nm}$ \\
Input power range & $P_{\text {Pump }}$ & -40 to $10 \mathrm{dBm}$ & -36 to $3 \mathrm{dBm}$ \\
Probe wavelength & $\lambda_{\text {Probe }}$ & - & $1554 \mathrm{~nm} / 1558 \mathrm{~nm}$ \\
Probe power & $P_{\text {Probe }}$ & - & $0 \mathrm{dBm}$ \\
Bias current & $I_{c}$ & $130 \mathrm{~mA}$ & $200 \mathrm{~mA}$ \\
Active region length & $L$ & $600 \mu \mathrm{m}$ & $600 \mu \mathrm{m}$ \\
Confinement factor & $\Gamma$ & 0.45 & 0.45 \\
\hline
\end{tabular}

$$
\begin{aligned}
& -\frac{2 \Gamma}{h d W}\left\{\sum_{j=0}^{N_{m-1}} \frac{g\left[N_{i}(z), v_{j}\right] K_{j}}{v_{j}}\right. \\
& \left.\times\left[P_{\mathrm{ASE}}^{+}(N(Z))+P_{\mathrm{ASE}}^{-}(N(Z))\right]\right\},
\end{aligned}
$$

where $I$ is the injected current to the amplifier, $e$ is electron charge, and $h$ is the plank's constant. $\Gamma$ is the confinement factor, $p_{k}$ represents the power of the different lights in SOA, and the subscript $k=s, p, a$ stands for signal, probe, and assist light, respectively. $P_{\mathrm{ASE}}^{+}$and $P_{\mathrm{ASE}}^{-}$represent the noise power for the forward and backward directions. $R$ is the radiative and nonradiative carrier recombination rates. Additionally, $K_{j}$ is the filter factor, which represents the fraction of spontaneously emitted photons that coupled into the guided mode [23]. The parameters used in this work are shown in Table 2.

Two factors was considered to validate the performance of the system.

3.1. Conversion Efficiency. To examine the effectiveness of $\mathrm{WC}$, the CE of the scheme was presented for two probe signals, which were at $1554 \mathrm{~nm}$ and $1558 \mathrm{~nm}$ to the pump signal wavelength $1541 \mathrm{~nm}$. CE $(\eta)$ is defined as the ratio between the converted signal power $P_{\text {out }}$ and input pump power $P_{\text {in }}$ that can be measured by (3) $[29,30]$.

$$
\eta=\log \frac{P_{\text {out }}\left(\lambda_{\text {conv }}\right)}{P_{\text {in }}\left(\lambda_{\text {pump }}\right)} .
$$

3.2. The Q-Factor. Q-factor [31] offers a suitable measure of the overall system performance and can be used based on optical eye diagram. The parameter values were expressed in $\mathrm{dB}$, with quality factor more than 6 corresponding to acceptance performance. Q-factor is defined below:

$$
Q=\frac{H_{L}-L_{L}}{\sigma_{H}+\sigma_{L}},
$$

where $H_{L}$ is the average high power level, $L_{L}$ is the average low power level, and $\sigma_{H}$ and $\sigma_{L}$ are the high and low power level standard deviations, respectively.

\section{Result and Discussion}

The setup of proposed system is displayed in Figure 1. In this work the Opti.System software was used to prove and demonstrate the performance of one to two XGM-WC based on TW-SOA. The main parameters are summarized in Table 2. At the optimum operating point, the probes power was kept constant at a fixed value to obtain the best conversion results. Figures 2(a) and 2(b) represent the system response.

The spectrum analyzer was used to display the waveform's state. Figure 2(a) shows the output spectrum after SOA and here the converted channels $1554 \mathrm{~nm}$ and $1558 \mathrm{~nm}$ and fourwave mixing (FWM) signals were observed in Figure 2(b). The amplitude of FWM products was decreased using a $4 \mathrm{~nm}$ spacing between probes. It is clearly shown that the FWM products amplitude was weaker than the probe channels, and then it filters out at WDM DMUX. The main goal of this paper is to implement $\mathrm{WC}$ at $\mathrm{ONU}$ and examine the opportunity of power splitting ratio. To do so, the system was analyzed in terms of conversion efficiency and $Q$-factor.

The data forms captured for input pump and output of the first user of original and converted wavelengths are shown in Figure 2(b). The findings clearly indicated that the two converted lights (iii and iv) carried information contrary to the input signal (i) while the equivalent data was represented in (ii) for the original data signal. Therefore, the converter can achieve two wavelengths simultaneously. Moreover, the original channel showed a better result.

4.1. Conversion Efficiency Measurements. The conversion efficiency of the configuration was measured using (3) for two input probes $1554 \mathrm{~nm}$ and $1558 \mathrm{~nm}$ with $1541 \mathrm{~nm}$ pump wavelength. The results are illustrated in Table 3.

As seen in Table 3, the results achieved in this work were in agreement with previous work discussed by [24, 27, 29]. CE was inversely proportional to the pump signal power over the whole spectral range; as the pump signal power value increases, the $\mathrm{CE}$ value will decrease. In addition, the $\mathrm{CE}$ for the furthest wavelength from pump is higher than the nearest wavelength by about $1 \mathrm{~dB}$ for all pump values. Moreover the maximum amount of $\mathrm{CE}$ at $1558 \mathrm{~nm}$ with $-6 \mathrm{dBm}$ pump power was $13.47 \mathrm{~dB}$ while the minimum value at $1554 \mathrm{~nm}$ with $3 \mathrm{dBm}$ pump power was $3.30 \mathrm{~dB}$. 


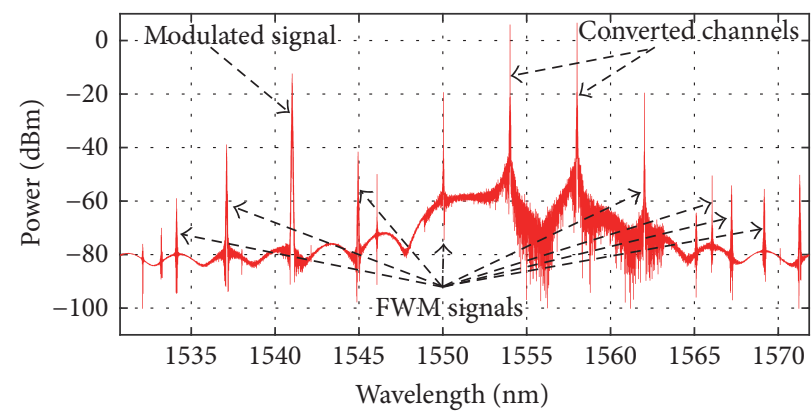

(a)

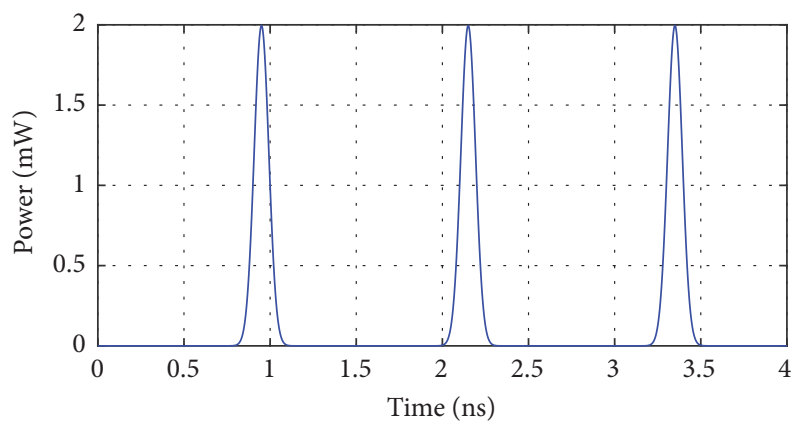

(i)

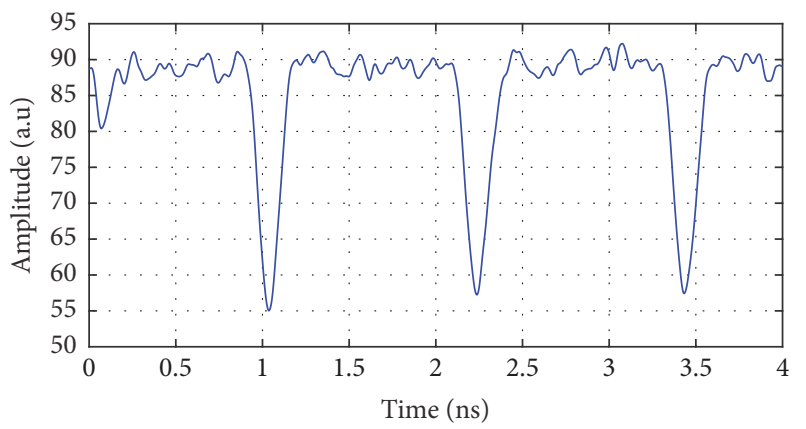

(iii)

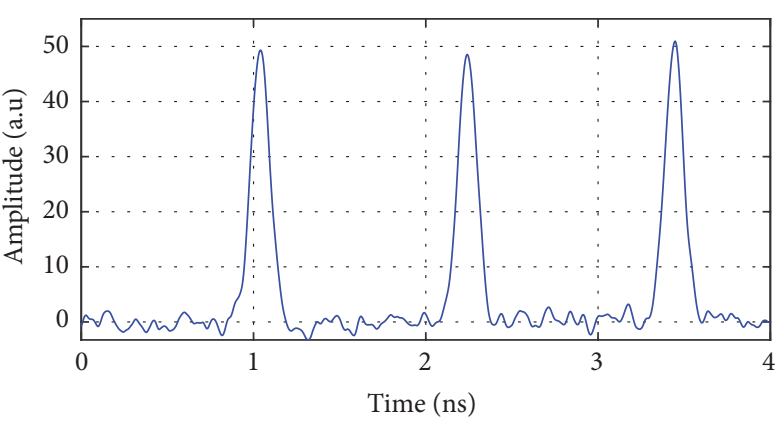

(ii)

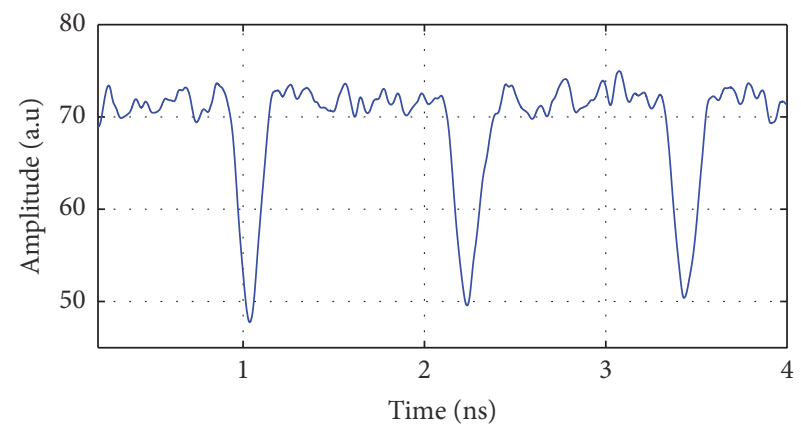

(iv)

(b)

FIgURE 2: SOA output shape. (a) The TW-SOA output spectrum and (b) representation of wavelength converter.

TABle 3: Conversion efficiency measurements.

\begin{tabular}{lcccc}
\hline Input power $(\mathrm{dBm})$ & \multicolumn{2}{c}{$\lambda 1=1554 \mathrm{~nm}$} & \multicolumn{2}{c}{$\lambda 2=1558 \mathrm{~nm}$} \\
$\mathrm{CE} / \mathrm{dB}$ \\
\hline-6 & Output power $(\mathrm{dBm})$ & $\mathrm{CE} / \mathrm{dB}$ & 12.54 & Output power $(\mathrm{dBm})$ \\
-3 & 6.54 & 9.49 & 7.47 & 13.47 \\
0 & 6.49 & 6.41 & 7.32 & 7.41 \\
3 & 6.41 & 3.30 & 7.21 & \\
\hline
\end{tabular}

4.2. The Impact of Pump Power. Q-factor performance analysis of channels was processed by XGM-SOA followed by wavelength DeMUX relative to the fluctuation of the pump power which was presented for three considered positions in the system configuration. This method is able to copy data from input pump signal onto the probes wavelengths; then using optical power splitter the structure achieved 1-to-64 splitting ratio with the $Q$-factor of better than six (equivalent to BER of less than $10^{-9}$ ) at the pump power $3 \mathrm{dBm}$. The $Q$ values measurements are shown in Figure 3. The $Q$-values were calculated at three different positions of SOA. Firstly, the WC was applied at back to back (a). Secondly, SOA was installed at $20 \mathrm{~km}$ (b). After that the third test (c) run at $20 \mathrm{~km} \mathrm{SMF}+1: 64$ optical power splitter. Measurements of the pump and two converted signals were studied and it was illustrated that the $Q$-factor values have different achievement 


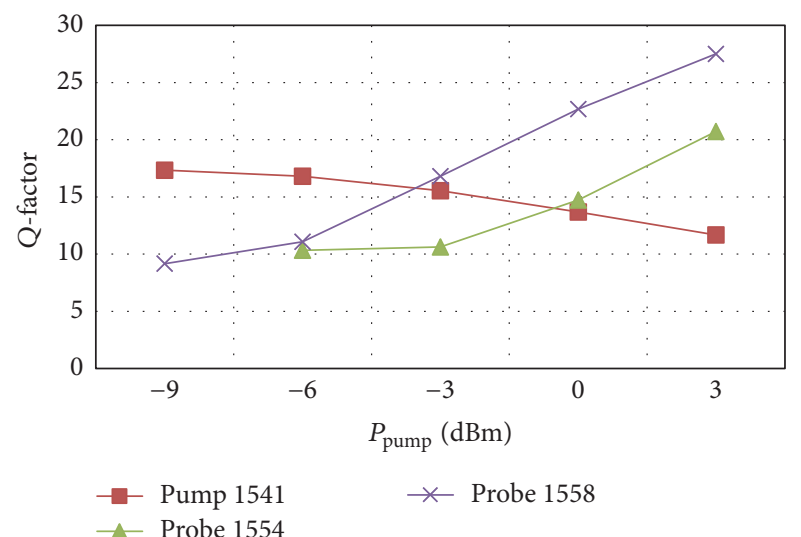

(a)

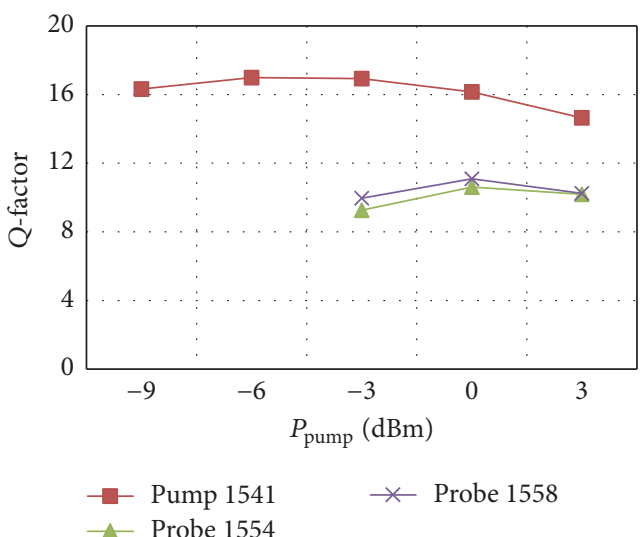

(b)

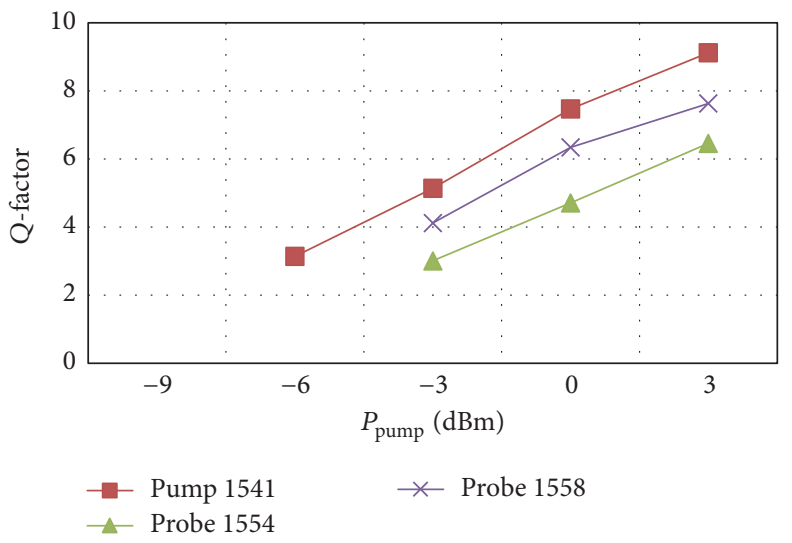

(c)

FIGURE 3: Impact of pump power: (a) fiber to fiber, (b) after $20 \mathrm{~km}$ fiber link, and (c) after $20 \mathrm{~km}+$ optical splitter.

at the three different positions as seen in Figures 3(a), 3(b), and $3(\mathrm{c})$. One point noticed here was the $Q$ value of the transmitted signal is declined with increasing pump power due to the SOA work in the saturation region. Nevertheless, the $Q$ values record acceptable result more than 8 over the power range between -9 and $3 \mathrm{dBm}$ for both pump and probes, as shown in Figures 3(a) and 3(b) for a full range of the pump. The $Q$ values had a great result above 9 back to back and $20 \mathrm{~km}$ fiber, respectively, but for Figure 3(c) the $Q$ values proportionally increase as the pump power increased for all frequencies. Another point can be noted that the $Q$ value of the pump wavelength $1541 \mathrm{~nm}$ marked square was inversely proportional with the pump power in Figure 3(a). Contrarily it has direct proportion in Figure 3(c) and it fluctuated between minimum 14.64 and maximum 16.99 in Figure 3(b).

Comparing the two probes response, the $1558 \mathrm{~nm}$ purple color has better performance than $1554 \mathrm{~nm}$ green color, especially for Figures 3(a) and 3(c), but they are nearly similar in Figure 3(b). As for Figure 3(c) we can note that the probe $1554 \mathrm{~nm}$ can apply for one value of power $3 \mathrm{dBm}$ while the other probe $1558 \mathrm{~nm}$ gets advantages and is capable of working at $3 \mathrm{dBm}$ and $0 \mathrm{dBm}$ also. In addition, results showed that some values of the $Q$ dropped below six after optical power splitter was installed in the system. For that, the impact of optical power splitter (OPS) was obtained in the following section.

4.3. The Impact of Splitting Ratio. To identify the maximum splitting ratio that the system can afford, we proposed and investigated the effect of splitting ratio of $1: 16,1: 32$, and 1:64 for $1554 \mathrm{~nm}$ and $1558 \mathrm{~nm}$. Figure 4 describes the $Q$ variation of converted probe wavelengths due to pump power dependence for Figure 1(c) configuration after power splitter was installed (SOA current: $200 \mathrm{~mA}$, pump power range: $-6 \mathrm{dBm}$ to $3 \mathrm{dBm}$, and probes power $1554 \mathrm{~nm}$ and $1558 \mathrm{~nm}$ : $0 \mathrm{dBm}$ each).

Figures 4(a) and 4(b) remark that the values of $Q$ for $1558 \mathrm{~nm}$ are better than the results of $1554 \mathrm{~nm}$ at all points. Qfactor of $1558 \mathrm{~nm}$ wavelength converted signal is greater than 6 for three states of splitting ratio at all values of pump power, except for one point which is at $-3 \mathrm{dBm}$ for $1-64$, while the $1554 \mathrm{~nm}$ wavelength has acceptable $Q$-factor values for 1-16 splitting ratio, but for 1:64 line one value passed the test at $3 \mathrm{dBm}$ as compared to two values at 0 and $3 \mathrm{dBm}$.

By referring to the results, in order to increase the capacity and make full use of the system the sequence of the inverter data from converted channels should change before sending it simultaneously to each user, possibly using polarizationdiscriminating delay interferometer (PI-DI) presented in 


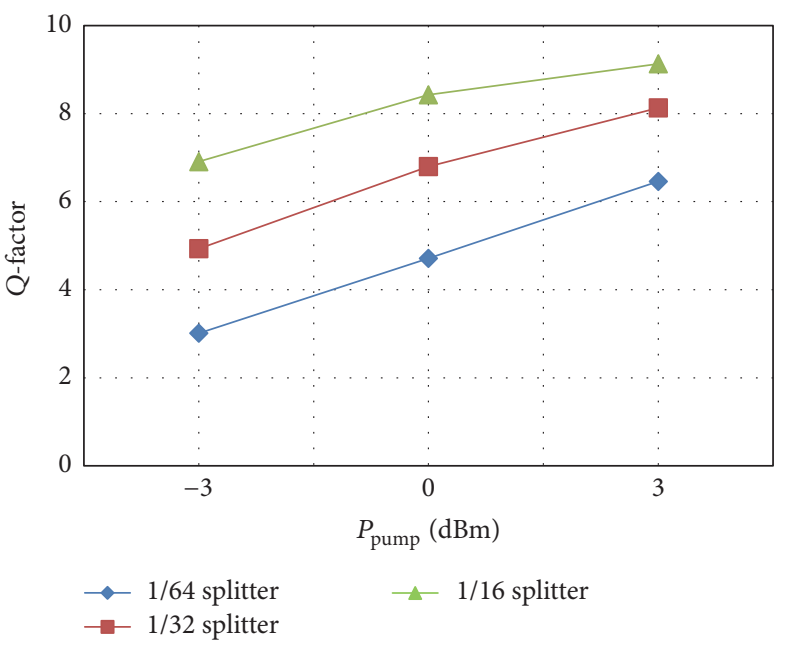

(a)

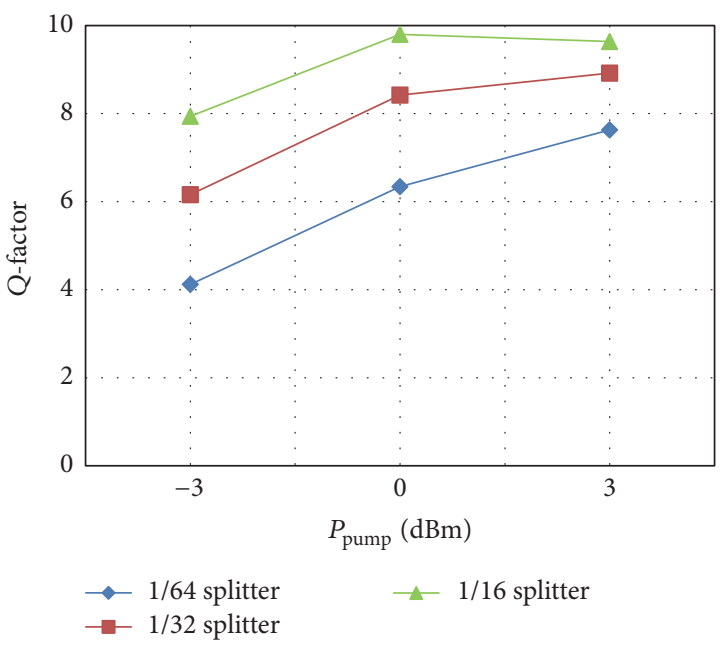

(b)

FIGURE 4: Impact of optical power splitter: (a) $1554 \mathrm{~nm}$ wavelength and (b) $1558 \mathrm{~nm}$ wavelength.

[32-34]. The scheme can be employed for the pump power of $3 \mathrm{dBm}$ to provide 1 to 2 XGM-WC with 1:64 splitting ratio at $20 \mathrm{~km}$. The results proved that the highest number of users can be supported at 192 with a speed of $156 \mathrm{Mb} / \mathrm{s}$ for each client using one optical line terminal (OLT). This result gives the opportunity to reduce the overall cost of the system. On the other hand, the downlink speed can be doubled if $1: 32$ splitter is used. Depending on the user's demands the downstream speed of customers can be $625 \mathrm{Mb} / \mathrm{s}$ for $1: 16$ splitting ratio or $1.25 \mathrm{~Gb} / \mathrm{s}$ for $1: 8$ splitter. The advantage of configuration was avoiding the use of erbium-doped fiber amplifier (EDFA) in the central office and/or at ONU. Besides, the system can work coexistence with standards of optical networks and provide the appropriate development for current demands and far away from unneeded capacity.

\section{Conclusion}

The XGM-WC was verified at three different positions. The system presents a 1-to-2-wavelength conversion method. The configuration can perform wavelength converter and capacity duplication concurrently at $10 \mathrm{~GB} / \mathrm{s}$ by using a single SOA based on XGM that has advantages in terms of conversion efficiency. Outcomes confirmed that the demonstrated technique can copy the input pump signal into two wavelengths $1554 \mathrm{~nm}$ and $1558 \mathrm{~nm}$ simultaneously. Additionally, the converted channels are able to split into 64 users with satisfactory performance at $3 \mathrm{dBm}$ pump power with $Q$ values better than 6. Finally, by using the several numbers of sources and probes, the system is able to provide a high capacity network. We believe that system like this will be a good proposal for access networks demands.

\section{Conflicts of Interest}

The authors declare that they have no conflicts of interest.

\section{Acknowledgments}

The authors would like to thank Universiti Kebangsaan Malaysia (UKM) for its full support.

\section{References}

[1] H.-Y. Chen, C.-C. Wei, I.-C. Lu, H.-H. Chu, Y.-C. Chen, and J. Chen, "High-capacity and high-loss-budget OFDM long-reach PON without an optical amplifier [invited]," Journal of Optical Communications and Networking, vol. 7, no. 1, pp. A59-A65, 2015.

[2] M. Maier, "The escape of Sisyphus or what "Post NG-PON2" should do apart from neverending capacity upgrades," Photonics, vol. 1, no. 1, pp. 47-66, 2014.

[3] B. Lannoo, G. Das, A. Dixit, D. Colle, M. Pickavet, and P. Demeester, "Novel hybrid WDM/TDM PON architectures to manage flexibility in optical access networks," Telecommunication Systems, vol. 54, no. 2, pp. 147-165, 2013.

[4] E. Harstead and R. Sharpe, "Future fiber-to-the-home bandwidth demands favor time division multiplexing passive optical networks," IEEE Communications Magazine, vol. 50, no. 11, pp. 218-223, 2012.

[5] C. V. Mobile, Cisco Visual Networking Index: Global Mobile Data Traffic Forecast Update, 2015-2020, Cisco Systems, San Jose, Calif, USA, 2016.

[6] S. Kumar, I. B. Pauria, and A. Singhal, "Optical fiber communication system performance using MZI switching," International Journal of Soft Computing and Engineering, vol. 2, no. 3, pp. 98107, 2012.

[7] K. E. Zoiros, "All-optical logic gates with quantum-dot semiconductor optical amplifiers," in Proceedings of the 15th International Conference on Transparent Optical Networks (ICTON '13), pp. 1-4, June 2013.

[8] H. Hasegawa, M. Funabashi, N. Yokouchi, K. Kiyota, and K. Maruyama, "Design and fabrication of semiconductor optical amplifier with low noise figure," in Proceedings of the 15th OptoElectronics and Communications Conference (OECC '10), pp. 204-205, IEEE, July 2010. 
[9] C. Schubert, R. Ludwig, and H.-G. Weber, "High-speed optical signal processing using semiconductor optical amplifiers," Journal of Optical and Fiber Communications Reports, vol. 2, no. 2, pp. 171-208, 2005.

[10] M. S. Ab-Rahman, "A review of the configuration and performance limitation parameters in optical amplifiers," Optica Applicata, vol. 44, no. 2, pp. 251-266, 2014.

[11] X. Li, J. Jin, H. Li, and Q. Zhang, "Study of all-optical logic XOR gate based on linear optical amplifier cross-gain modulation," Optica Applicata, vol. 45, no. 4, pp. 447-457, 2015.

[12] R. Randhawa, S. Singh, J. S. Sohal, and R. S. Kaler, "Wavelength converter using semiconductor optical amplifier Mach-Zehnder interferometer based on XPM at $40 \mathrm{~Gb} / \mathrm{s}$ for future transport networks," Fiber and Integrated Optics, vol. 28, no. 2, pp. 154-169, 2009.

[13] N. Yan, I. T. Monroy, H.-D. Jung, T. Koonen, A. Teixeira, and T. Silveira, "Optical multicast technologies by multi-wavelength conversion for optical routers," in Proceedings of the International Conference on Communication Technology (ICCT '06), pp. 1-4, November 2006.

[14] T. Pan, P. Li, S. Huang, and Z. Zhao, "Multiwavelength converter exploiting cross-gain modulation in SFRL," in Proceedings of the SPIE/OSA/IEEE Asia Communications and Photonics, pp. 830822-830822-6, International Society for Optics and Photonics, November 2011.

[15] N. Yan, T. Silveira, A. Teixeira et al., " $40 \mathrm{Gbit} / \mathrm{s}$ wavelength multicast via SOA-MZI and applications," Electronics Letters, vol. 43, no. 23, pp. 1300-1302, 2007.

[16] Z.-Q. Hui, B. Zhang, and J.-G. Zhang, "All-optical NRZ-to-RZ format conversion at $10 \mathrm{Gbit} / \mathrm{s}$ with 1-to-4 wavelength multicasting exploiting cross-phase modulation \& four-wave-mixing in single dispersion-flattened highly nonlinear photonic crystal fiber," Journal of Modern Optics, vol. 63, no. 8, pp. 724-734, 2016.

[17] C. Meuer, H. Schmeckebier, G. Fiol et al., "Cross-gain modulation and four-wave mixing for wavelength conversion in undoped and $\mathrm{p}$-Doped $1.3-\mu \mathrm{m}$ quantum dot semiconductor optical amplifiers," IEEE Photonics Journal, vol. 2, no. 2, pp. 141151, 2010.

[18] B. H. L. Lee, R. Mohamad, and K. Dimyati, "Performance of alloptical multicasting via dual-stage XGM in SOA for grid networking," IEEE Photonics Technology Letters, vol. 18, no. 21, pp. 2215-2217, 2006.

[19] J. del Val Puente, N. Yan, E. Tangdiongga, and T. Koonen, "Performance comparison of multi-wavelength conversion using SOA-MZI and DSF for optical wavelength multicast," in Optical Network Design and Modeling, pp. 1-10, Springer, 2007.

[20] N. A. Awang, H. Ahmad, A. A. Latif, M. Z. Zulkifli, Z. A. Ghani, and S. W. Harun, "Wavelength conversion based on FWM in a HNLF by using a tunable dual-wavelength erbium doped fibre laser source," Journal of Modern Optics, vol. 58, no. 7, pp. 566572, 2011.

[21] M. Hattori, K. Nishimura, R. Inohara, and M. Usami, "Bidirectional data injection operation of hybrid integrated SOAMZI All-optical wavelength converter," Journal of Lightwave Technology, vol. 25, no. 2, pp. 512-519, 2007.

[22] N. Yan, J. del Val Puente, T. G. Silveira et al., "Simulation and experimental characterization of SOA-MZI-based multiwavelength conversion," Journal of Lightwave Technology, vol. 27, no. 2, pp. 117-127, 2009.
[23] G. Chen and S. Pan, "A UWB over fiber system based on frequency-dependent gain saturation in a RSOA," in Proceedings of the IEEE Radio and Wireless Symposium, pp. 133-135, Austin, Tex, USA, January 2013.

[24] R. Bonk, H. Schmuck, W. Poehlmann, and T. Pfeiffer, "Beneficial OLT transmitter and receiver concepts for NG-PON2 using semiconductor optical amplifiers [Invited]," Journal of Optical Communications and Networking, vol. 7, no. 3, pp. A467-A473, 2015.

[25] M. J. Connelly, "Wideband semiconductor optical amplifier steady-state numerical model," IEEE Journal of Quantum Electronics, vol. 37, no. 3, pp. 439-447, 2001.

[26] H. Wang, J. Wu, and J. Lin, "Studies on the material transparent light in semiconductor optical amplifiers," Journal of Optics A: Pure and Applied Optics, vol. 7, no. 9, pp. 479-492, 2005.

[27] A. Abd El Aziz, W. P. Ng, Z. Ghassemlooy, M. H. Aly, R. Ngah, and M. F. Chiang, "Impact of signal wavelength on the semiconductor optical amplifier gain uniformity for high speed optical routers employing the segmentation model," in Proceedings of the 10th International Conference on Information Sciences, Signal Processing and their Applications (ISSPA '10), pp. 259-262, May 2010.

[28] A. A. El Aziz, E. K. El Nayal, M. H. Aly, A. AboulSeoud, and $\mathrm{W}$. Ng, "Impact of amplified spontaneous emission on the travelling wave semiconductor optical amplifier performance," in Proceedings of the 2nd International Workshop on Optical Wireless Communications (IWOW '13), pp. 123-127, IEEE, 2013.

[29] R. D. O. Ribeiro, M. J. Pontes, M. T. M. R. Giraldi, and M. C. R. Carvalho, "Characterisation of all-optical wavelength conversion by cross-gain modulation of ASE on a SOA," in Proceedings of the SBMO/IEEE MTT-S International Microwave and Optoelectronic Conference, pp. 218-221, July 2005.

[30] A. Aulakh and K. S. Malhi, "To investigate the characteristics parameters of semiconductor optical amplifier based on wavelength converters for all optical networks," International Journal of Computer Applications, vol. 95, no. 19, pp. 37-41, 2014.

[31] J. Contreras-Torres and R. Gutierrez-Castrejon, "Performance analysis of an all-optical wavelength converter using a semiconductor optical amplifier simulator," in Proceedings of the 2nd International Conference on Electrical and Electronics Engineering, pp. 97-100, IEEE, Mexico City, Mexico, September 2005.

[32] R. Inohara, K. Nishimura, M. Tsurusawa, and M. Usami, "Experimental analysis of cross-phase modulation and cross-gain modulation in SOA-injecting CW assist light," IEEE Photonics Technology Letters, vol. 15, no. 9, pp. 1192-1194, 2003.

[33] X. Tang, N. Y. Kim, and J. C. Cartledge, "Noise transfer characteristics in a semiconductor optical amplifier with application to wavelength conversion based on a delay interferometer," Journal of Lightwave Technology, vol. 26, no. 12, pp. 1715-1721, 2008.

[34] X. Zhao, C. Lou, and Y. Feng, "Optical signal processing based on semiconductor optical amplifier and tunable delay interferometer," Frontiers of Optoelectronics in China, vol. 4, no. 3, pp. 308-314, 2011. 

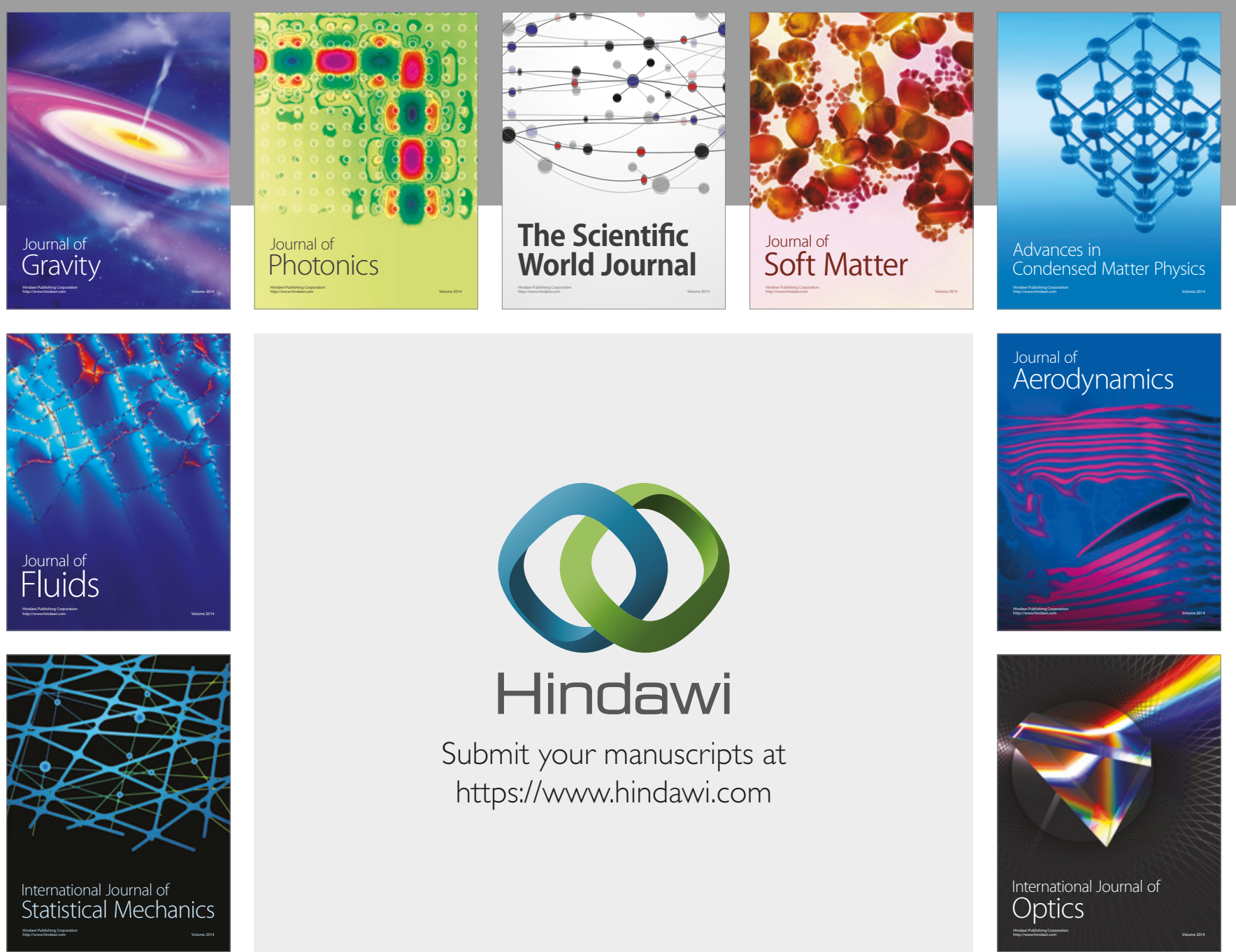

Submit your manuscripts at

https://www.hindawi.com
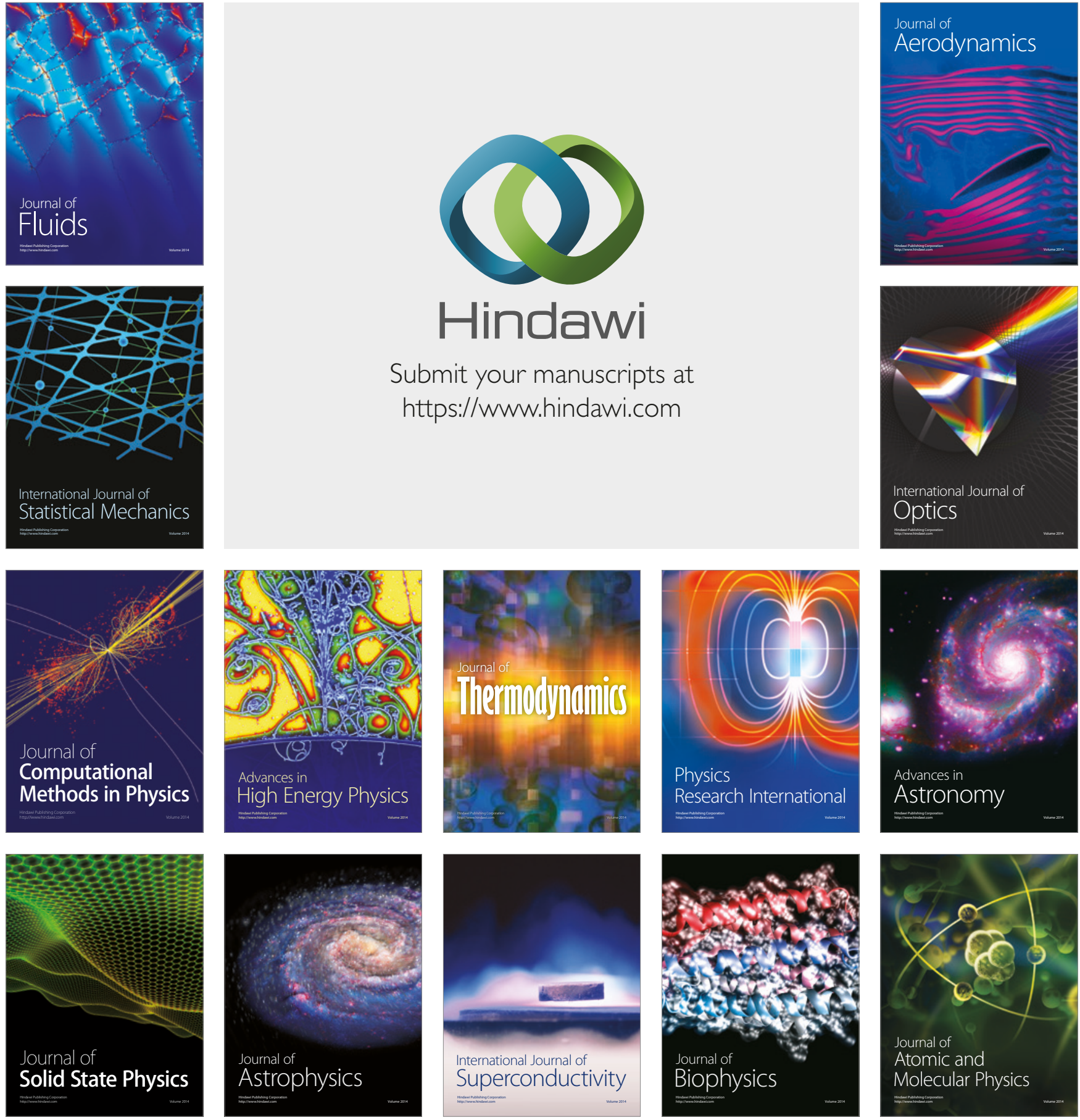